\title{
Assessment of Serum Magnesium Level in Type 2 Diabetes Mellitus with Diabetic Foot Ulcers (Grade I and II) at Nawabshah, Pakistan
}

\author{
Anwar Ali Jamali ${ }^{*}$, Ghulam Mustafa Jamali ${ }^{1}$, Niaz Hussain Jamali ${ }^{2}$, Bhojo Mal Tanwani ${ }^{3}$, \\ Arslan Ahmer Rajput ${ }^{2}$, Ameer Ali Jamali ${ }^{4}$ \\ ${ }^{1}$ Department of Medicine, Peoples University of Medical and Health Sciences for Women, Nawabshah, Pakistan \\ ${ }^{2}$ Institute of Pharmaceutical Sciences, Peoples University of Medical and Health Sciences for Women, Nawabshah, Pakistan \\ ${ }^{3}$ Deapartment of Physiology, Peoples University of Medical and Health Sciences for Women, Nawabshah, Pakistan \\ ${ }^{4}$ Deapartment of Paediatrics Medicine, Peoples University of Medical and Health Sciences for Women, Nawabshah, Pakistan \\ Email: ^jamalianwarali@gmail.com
}

How to cite this paper: Jamali, A.A., Jamali, G.M., Jamali, N.H., Tanwani, B.M., Rajput, A.A. and Jamali, A.A. (2018) Assessment of Serum Magnesium Level in Type 2 Diabetes Mellitus with Diabetic Foot Ulcers (Grade I and II) at Nawabshah, Pakistan. International Journal of Clinical Medicine, 9, 104-116.

https://doi.org/10.4236/ijcm.2018.92011

Received: January 24, 2018

Accepted: February 25, 2018

Published: February 28, 2018

Copyright (c) 2018 by authors and Scientific Research Publishing Inc. This work is licensed under the Creative Commons Attribution International License (CC BY 4.0).

http://creativecommons.org/licenses/by/4.0/

\section{(c) (i) Open Access}

\begin{abstract}
Diabetes Mellitus is a metabolic disorder increasing morbidity and mortality worldwide, which needs exact identification and proper management. Aim of this study was to analyze the serum $\mathrm{Mg}$ (magnesium) level in patients with Type 2 Diabetes Mellitus with grade I \& II diabetic foot ulcers. This descriptive cross sectional study was conducted at Medicine Department, $\mathrm{PMCH}$ Nawabshah from June 2015 to December 2016. A total of 110 Type 2 Diabetes Mellitus with foot ulcer patients, 51 with grade I and 59 with grade II out of total were included by purposive sampling. After consultation, subjects were categorized as gender, age, Type $2 \mathrm{DM}$ and foot ulcer duration, foot ulcer grading and grouping for analyses. Wagner's classification of diabetic foot ulcers used to analyze the data and blood samples were collected for research purpose in fasting state for serum Magnesium level analyses. Out of 110, 67 (65.5\%) males and 43 (34.5\%) females were reported with Type 2 diabetic patients. Hypomagnesaemia was reported in 59\% patients out of total, 24 found with grade I and 38 found with grade II from the studied subjects. P value $\leq$ 0.000 was in the studied population in relation to hypomagnesaemia. In conclusion, Hypomagnesaemia is common in Type 2 Diabetes Mellitus patients with grade I \& II foot ulcers. As the duration of Diabetes along with duration of diabetic foot ulcer in Grade I and II increases, the level of serum magnesium decreases. As the duration of Diabetes Mellitus increases, the severity of complications might also increase.
\end{abstract}

\section{Keywords}

Magnesium, Hypomagnesaemia, Type 2 Diabetes Mellitus, Foot Ulcers 


\section{Introduction}

Diabetes Mellitus is a universal metabolic disorder increasing morbidity and mortality since centuries [1]. It manifests as disturbed metabolism with raised blood sugar due to absolute or relative deficiency or resistance to insulin. There are the identified possible elements for growth of diabetes mellitus [2]. Foot ulcer in diabetes is a prolonged damage of the skin occurs in the feet of diabetes patients. During the life time, foot ulcer might develop 1 in every 4 among diabetes patients [3]. Neuropathic ulcer or Ischemic ulcer might be associated with Diabetic foot ulceration, however, other causal or risk factors, e.g. trauma can also be the ultimate etiological pathways [4].

Diabetes prevalence in Pakistan was found in 5,200,000 people approximately in the year 2000 and might be reach at 139,000,000 approximately in the year 2030 [5]. Magnesium is a cofactor in the cell membrane transporting mechanism of glucose and different important enzymes involved in carbohydrate oxidation [6]. Phuong-Chi et al. showed that poor glycemic control has been linked with hypomagnesaemia resulting in various complications e.g. neuropathy and diabetic foot ulcers. The frequency of hypomagnesaemia in DM type 2 was $13.5 \%$ to $47.7 \%$ $(P=0.02)$ [7]. Diabetic foot ulcer presents as severe problem of DM and as first appearance of diabetes mellitus which was undiagnosed previously [8]. A study revealed that grade 2, 3 and 4 of diabetes complications were cured in $17 \%$ out of total studied population with conservative treatment through antibiotics [9]. Magnesium supplementation is valuable in management of complication prevention [10].

Aim of this study was to analyze the serum Mg (magnesium) level in patients with Type 2 Diabetes Mellitus with grade I \& II diabetic foot ulcers. This study will also help in reduction of complications related to Magnesium deficiency to reduce the morbidity and mortality.

\section{Materials and Methods}

This descriptive cross-sectional study was carried out in the period from June 2015 to December 2016 at Medical Department, PMCH Nawabshah after approval of Ethics Committee PMCH Hospital. A written consent was obtained from the participants. A total of 110 Type 2 DM patients with foot ulcers (diabetic) according Wagner's gratifying criterion of $>40$ years age with grade I and II foot ulcers were selected by purposive sampling technique at Confidence Interval (CI) of $95 \%$ and margin of error $d-0.05$. A written signed consent form was obtained and the questionnaire designed for the demographic or socioeconomic, past clinical and medication history of disease including their lab reports and all relevant data was filled from every participant of this study. Moreover, the venous blood was collected in fasting from Type 2 DM patients and it was analyzed in laboratory for Magnesium concentrations by using Xylidyl Blue method with 3338 Merck test Kit, below $<1.5 \mathrm{mEq} / 1$ Level. 


\subsection{Inclusion Criteria}

Cut-off values are Magnesium levels: normal 1.5 - $2.5 \mathrm{mEq} / \mathrm{L}$, Hypomagnesae$\mathrm{mia}<1.5 \mathrm{mEq} / \mathrm{L}$ and Hypermagnesemia $>2.5 \mathrm{mEq} / \mathrm{L}$ [11] [12] [13] [14].

\subsection{Exclusion Criteria}

Patients with complications of diabetes like diabetic keto-acidosis, lactic-acidosis, hypoglycemia, HONK; gestational DM, CVA, dialysis patients, magnesium drugs supplementation, foot ulcers other than grade I and II were excluded.

\subsection{Diagnosis of Diabetes Mellitus Type 2}

Type 2 DM diagnosed through clinical history, examination and investigations and OHA and insulin, medical records and according American Diabetic Association Criteria [15].

- FBS values of $>126 \mathrm{mg} / \mathrm{dL}$ on two separate occasions.

- Symptomatic patients, RBS of $>200 \mathrm{mg} / \mathrm{dL}$ suggests diabetes.

Diabetic foot ulcers: Grade-I superficial and Grade-II deep ulcers according to Wagner's grading [16].

Wagner's Classification

\begin{tabular}{cc}
\hline Grade of Diabetic Foot Ulcer & Complication of Diabetic Foot Ulcer \\
\hline 0 & Foot at increased hazard and no ulcer \\
1 & Ulcer (superficial) \\
2 & Cellulitis with deep ulcers \\
3 & Osteomyelitis ulcer \\
4 & Gangrene (patchy) \\
5 & Foot completely gangrenous \\
\hline
\end{tabular}

\subsection{Statistical Analysis}

Data was analyzed by using SPSS version 20.0. Frequency \& percentage were computed for categorical variables like gender and hypomagnesaemia. Mean and standard deviation calculated for variables (quantitative) like age. Magnesium significance was seen in age, gender, grade of ulcer, duration of T2 DM, Fasting Blood Sugar and Random Blood Sugar to assess the impact on outcomes.

\section{Results}

Out of total $110(100 \%)$ subjects of Type 2 DM with foot ulcer patients, no any patient was seem to be missing in this study. 72 (65.5\%) males and $38(34.5 \%)$ females. In our findings, 51 (46.4\%) subjects found with grade I and 59 (53.6\%) with grade II diabetic foot ulcer $(\mathrm{P}=0.000) .11(10 \%)$ were young, $73(66.4 \%)$ middle age and $26(23.6 \%)$ were old age groups $(\mathrm{P}=0.033)$. Regarding literacy level, 29 (26.36\%) were uneducated, 53 (48.18\%) were at primary level, $15(13.63 \%)$ middle level, 2 (1.81\%) matriculation level, 5 (4.54\%) intermediate level and 6 
(5.45\%) patients were at graduate level $(\mathrm{P}=0.034) .53(48.18 \%)$ presently had no any occupation, $25(22.72 \%)$ female were housewives, 18 (16.36\%) manual workers and $14(12.72 \%)$ were office workers $(\mathrm{P}=0.000)$. Marital status showed that 103 (93.63\%) patients were married whereas 7 (6.36\%) were un-married. Majority, 86 (78.18\%) of patients included in this study were from rural community and the remaining $24(21.82 \%)$ belonged to urban community $(\mathrm{P}=0.531)$, Body Mass Index was normal in $66(60 \%)$, overweight $41(37.3 \%)$ and $3(2.7 \%)$ patients were obese (Figure 1).

This study showed that the mean of age was found $55.90 \pm 9.522$, the median of age was 56.00, minimum age 30 and maximum age was 70 years respectively $(\mathrm{P}=0.000) . \mathrm{HbA1C}$ was $9.09 \pm 1.9$ ( $\mathrm{P}$ value 0.000$)$, serum magnesium $1.43 \pm$ 0.234 (P value 0.022), Fasting Blood Sugar (FBS) was $126.19 \pm 25.40$ (P value $0.950)$ and Random Blood Sugar (RBS) was $278.85 \pm 62.03(\mathrm{P}=0.352)$ (Table 1).

Regarding duration of T2DM, 27 (24.54\%) patients were with $<05$ years of disease duration, $22(20 \%)$ were with 5 - 10 years of duration and $02(1.81 \%)$ found with $>10$ years of duration $(P=0.000)$. Serum magnesium level (S.M.L) was nor$\mathrm{mal}$ in $43(39.09 \%)$ volunteers and in $67(60.9 \%)$ patients were at below from the normal range of S.M.L ( $\mathrm{P}=0.000)$. 43 subjects ( 29 males and 14 females) were reported with normal S.M.L and 67 subjects (males 43 and 24 females) reported with hypomagnesaemia. It was detected that, as foot ulcer grade increases, the frequency of hypomagnesaemia increases, as shown in Figure $1 \&$ Table 2.

The association of hypomagnesaemia with grade 1 diabetic foot ulcer patients with the duration of diabetes < 05 years was reported in 13 (11.81\%), 10 (9.09\%) patients with hypomagnesaemia found among $05-10$ years of chronic Diabetic patients and $1(0.9 \%)$ patients with hypomagnesaemia found among $>10$ years of chronic Diabetic patients ( $\mathrm{P}$ value 0.000 ). The relation of duration with hypomagnesaemia in grade II diabetic foot ulcer patients with duration of diabetes < 05 years were $02(1.81 \%), 05(4.54 \%)$ patients had duration $05-10$ years and 36 $(32.72 \%)$ had duration of diabetes $>10$ years $(\mathrm{P}=0.000)$.

Hypomagnesaemia was present in 24 patients with grade- 1 and in 43 grade-II diabetic foot ulcer patients, whereas, normal serum magnesium levels observed in 27 subjects having grade-I and in 16 grade-II foot ulcers patients, statistically significance was observed at $\mathrm{P}$-value $<0.000$.

Out of 43 patients with diabetic foot ulcer grade I \& II, normal magnesium levels were seen in 15 ( 14 with grade I and 1 with grade II) patients with duration of diabetes $<05$ years, 26 ( 12 with grade I and 14 with grade II) with duration of $05-10$ years of DM and 02 ( 1 with grade I and 1 with grade II) with duration of 10 years of $\mathrm{DM}(\mathrm{P}=0.007)$.

An association amongst duration of foot ulcer and duration of diabetes was observed in this study, increase in the interval of T2DM also amplify hazard of hypomagnesaemia that was statically significant with $\mathrm{P}$-value $<0.000$ and simultaneously as the grade of foot ulcer progresses, the risk of hypomagnesaemia increases. Meanwhile, in grade II diabetic foot ulcer patients, 43 have hypomagnesaemia and 16 have normomagnesemia, statically significant with $\mathrm{P}$-value $<0.13$, 
Table 1. Statistical evaluation of different variables in patients.

\begin{tabular}{cccccc}
\hline $\begin{array}{c}\text { Statistical } \\
\text { Parameters }\end{array}$ & Age & Hb A1C & $\begin{array}{c}\text { Serum } \\
\text { Magnesium }\end{array}$ & $\begin{array}{c}\text { Fasting Blood } \\
\text { Sugar }\end{array}$ & $\begin{array}{c}\text { Random Blood } \\
\text { Sugar }\end{array}$ \\
\hline Mean & 55.90 & 9.0927 & 1.43 & 126.1909 & 278.8545 \\
Std. Error of Mean & 0.908 & 0.18184 & 0.022 & 2.42267 & 5.91489 \\
Median & 56.00 & 8.2000 & 1.40 & 123.5000 & 265.0000 \\
Mode & 60 & 8.00 & 1 & 142.00 & 210.00 \\
Std. Deviation & 9.522 & 1.90719 & .234 & 25.40913 & 62.03592 \\
Variance & 90.678 & 3.637 & 0.055 & 645.624 & 3848.456 \\
Range & 40 & 6.00 & 1 & 110.00 & 220.00 \\
Minimum & 30 Years & 6.50 & 1 & 85.00 & 190.00 \\
Maximum & 70 Years & 12.50 & 2 & 195.00 & 410.00 \\
P-Value & 0.000 & 0.000 & 0.022 & 0.950 & 0.352 \\
\hline
\end{tabular}

Table 2. Frequency distribution of magnesium level in different grades of foot ulcer and duration of diabetes in patients.

\begin{tabular}{|c|c|c|}
\hline Variable & Frequency $\mathrm{N}=110$ & Percentage $100 \%$ \\
\hline Normal Magnesium & 43 & 39.09 \\
\hline Hypomagnesaemia & 67 & 60.9 \\
\hline Male Normal Magnesium & 29 & 26.36 \\
\hline Female with Normal Magnesium & 14 & 12.72 \\
\hline Male with Hypomagnesaemia & 43 & 39.09 \\
\hline Female with Hypomagnesaemia & 24 & 21.81 \\
\hline Grade I Foot Ulcer & 51 & 46.36 \\
\hline G-I Normal Mg++ & 27 & 24.54 \\
\hline G-I Hypomagnesaemia & 24 & 21.81 \\
\hline Grade II Foot Ulcer & 59 & 53.63 \\
\hline G-II Normal Mg++ & 43 & 39.9 \\
\hline G-II Hypomagnesaemia & 16 & 14.54 \\
\hline Diabetes Mellitus Duration $<5$ Years & 27 & 24.54 \\
\hline Grade-I Ulcer Normal Mg++ & 14 & 12.72 \\
\hline Grade-II Ulcer Normal Mg++ & 1 & 0.9 \\
\hline Grade-I Ulcer Hypomagnesaemia & 13 & 11.81 \\
\hline Grade-II Ulcer Hypomagnesaemia & 2 & 1.81 \\
\hline Diabetes Mellitus Duration 5 - 10 Years & 22 & 20 \\
\hline Grade-I Ulcer Normal Mg++ & 12 & 10.9 \\
\hline Grade-II Ulcer Normal Mg++ & 14 & 12.72 \\
\hline Grade-I Ulcer Hypomagnesaemia & 10 & 9.09 \\
\hline Grade-II Ulcer Hypomagnesaemia & 5 & 4.54 \\
\hline
\end{tabular}




\section{Continued}

\begin{tabular}{ccc}
\hline Diabetes Mellitus Duration $>10$ Years & 2 & 1.81 \\
Grade-I Ulcer Normal Mg++ & 1 & 0.9 \\
Grade-II Ulcer Normal Mg++ & 1 & 0.9 \\
Grade-I Ulcer Hypomagnesaemia & 1 & 0.9 \\
Grade-II Ulcer Hypomagnesaemia & 36 & 32.72 \\
\hline
\end{tabular}

as demonstrated in (Table 2).

Statistical analysis showed a valid relation of magnesium level with T2DM. Correlation was significant in our data related to HbA1C with Pearson Correlation at $-0.319^{* *}$ and (Sig.2-tailed) 0.001. Continuity Correction value was at 3.556 and (Sig.2-tailed) 1.059. While, the Fisher's Exact Test Exact Sig. (2-sided) was 0.036 and Exact Sig. (1-sided) was 0.036 . This data was statistically significant (Table 3).

\section{Discussion}

Hypomagnesaemia is an important issue in T2DM needs research throughout the world. Western countries had paid attention on it. Clinical assessment and investigations are needed in context to assess relationship of blood glucose with insulin levels and counter-regulatory hormones with other important trace elements like copper, zinc, magnesium and other trace elements. Some tests are easily available and some not. In Pakistan, diagnostic tests are not freely available in government hospitals. Limited studies are available in on these setups. This study indicates that in adult's hypomagnesaemia is more pronounced in T2DM complications like foot ulcers. In this study, hypomagnesaemia is a common finding in the two sub groups of diabetic foot ulcer (grade I and II). Out of $65.5 \%$ of males and $36.5 \%$ of females, there was decreased ratio of females as compared with males, whereas, social back ground and less education were important factors to influence this (Figure 1).

An incident of hypomagnesaemia from $25 \%$ to $39 \%$ had been revealed in the subjects with diabetes (Type I \& II) [17] [18] [19] [20]. Mean level of HbA1C was 9.0927 in our findings. The mean FBS $126.1909 \pm 25.40913$ with statistically non-significant $(\mathrm{P}=0.950)$ and RBS $278.8545 \pm 62.03592(\mathrm{P}=0.352)$ were high in the studied population. In current study, normomagnesemia was found in 43 subjects and hypomagnesaemia was reported in 67 patients, as demonstrated in Table $1 \&$ Table 2 . High rate of hypomagnesaemia (51.88\%) was observed among diabetic patients, the results are more significant with others hypomagnesaemia in our studied subjects than other researches (25\% to 39\%) [21] [22] [23]. Hypomagnesaemia was present in 24 patients with grade- 1 and in 43 grade-II diabetic foot ulcer patients, whereas, normal serum magnesium levels observed in 27 subjects having grade-I and in 16 grade-II foot ulcers patients, statistically significance was observed at $\mathrm{P}$-value $<0.000$.

Unsatisfactory glycemic management is interconnected to Hypomagnesaemia 
Table 3. Cross tabulation hypomagnesaemia, duration of DM2, duration of foot ulcer and correlation of magnesium, FBS, RBS, $\mathrm{HbA} 1 \mathrm{C}$ and BMI

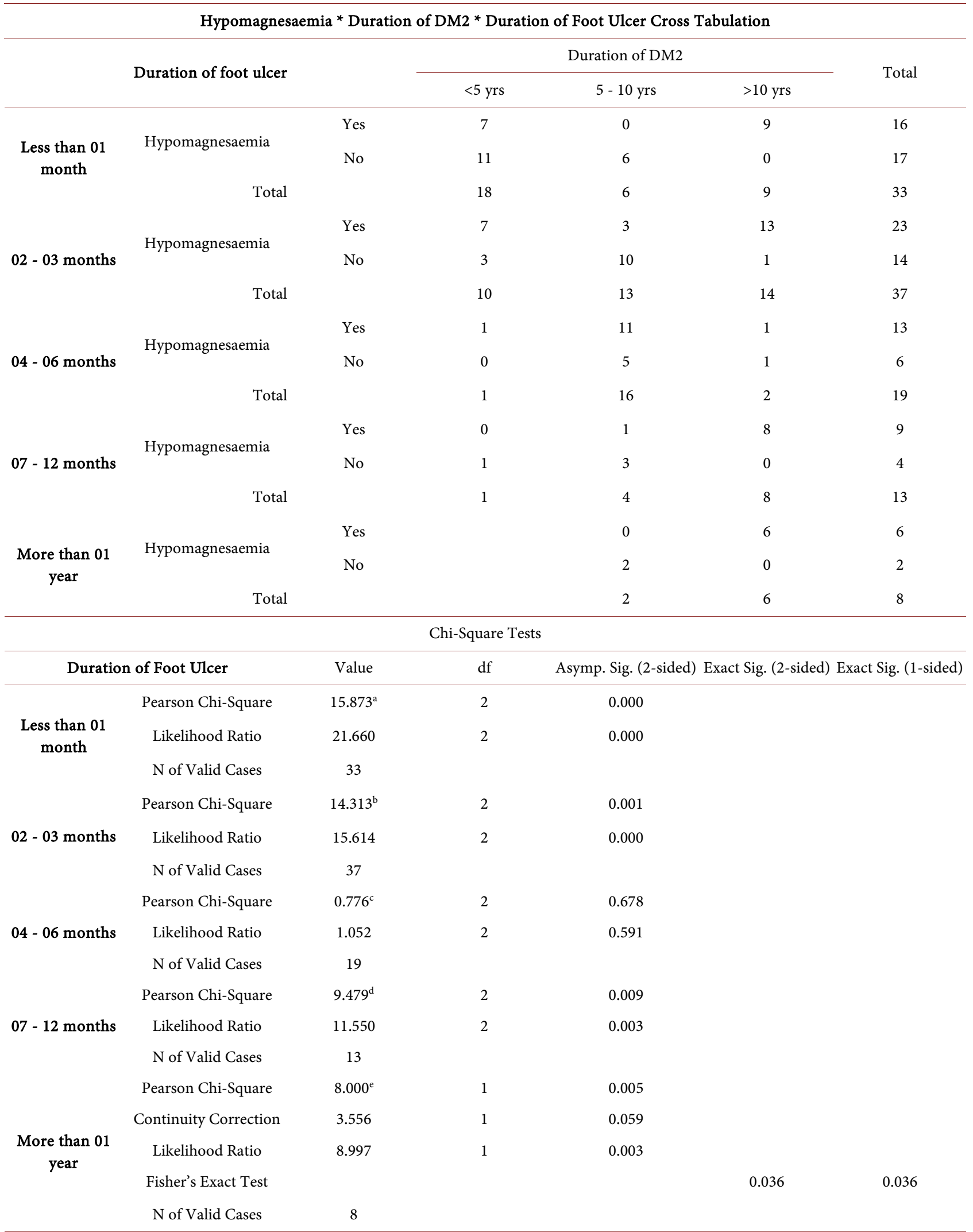




\begin{tabular}{|c|c|c|c|c|c|c|}
\hline \multicolumn{7}{|c|}{ Correlations } \\
\hline & & Serum Magnesium & Fasting Blood Sugar & Random Blood Sugar & Hemoglobin A1C & Body Mass Index \\
\hline Serum & Pearson Correlation & 1 & 0.12 & 0.04 & $-0.319^{* *}$ & 0.027 \\
\hline Magnesium & Sig. (2-tailed) & & 0.212 & 0.68 & 0.001 & 0.78 \\
\hline Fasting blood & Pearson Correlation & 0.12 & 1 & $0.755^{\star \star}$ & -0.045 & 0.018 \\
\hline Sugar & Sig. (2-tailed) & 0.212 & & 0 & 0.642 & 0.849 \\
\hline Random blood & Pearson Correlation & 0.04 & $0.755^{\star *}$ & 1 & -0.117 & 0.095 \\
\hline Sugar & Sig. (2-tailed) & 0.68 & 0 & & 0.222 & 0.324 \\
\hline Hemoglobin & Pearson Correlation & $-0.319^{* *}$ & -0.045 & -0.117 & 1 & -0.013 \\
\hline $\mathrm{AlC}$ & Sig. (2-tailed) & 0.001 & 0.642 & 0.222 & & 0.895 \\
\hline Body & Pearson Correlation & 0.027 & 0.018 & 0.095 & -0.013 & 1 \\
\hline Mass & Sig. (2-tailed) & 0.78 & 0.849 & 0.324 & 0.895 & \\
\hline Index & $\mathrm{N}$ & 110 & 110 & 110 & 110 & 110 \\
\hline
\end{tabular}

${ }^{*}$ Correlation is significant at the 0.01 level (2-tailed).

and urinary magnesium excretion. Glycosylated hemoglobin mean value of $\mathrm{HbA1C}$ level was $9.0927 \pm 1.90719(\mathrm{P}=0.000)$ in our findings. Unsatisfactory management of diabetes could be extra element for hypomagnesaemia in subjects [24] [25]. Insulin augments entry of magnesium within cells, when there is decrease in insulin levels this leads to hypomagnesaemia [26] [27]. Diabetes related complications are common in patients who had hypomagnesaemia [28]. We had found significant hypomagnesaemia in diabetic patients with foot ulcers. As evident of our study that, magnitude of hypomagnesaemia increases with the progression of complications, that serum magnesium was low in grade II diabetic foot ulcers as compared with grade I ulcers (Table 2).

A study suggested link between hypomagnesaemia, hyperglycemia and the complications of diabetes as concluded also in present study [29].

As duration of diabetes and foot ulcer increases the serum magnesium decreases [30]. Hypomagnesaemia also associated with complications like hypertension, abnormal glucose and lipid metabolism [31]. Study by Resnick et al. reported that hypomagnesaemia was found between 13.5\% - 47.7\% T2DM [32]. Here Hypomagnesaemia was found in 67/110 patients, on contrary non diabetic $2.5 \%$ to $15 \%$ were with hypomagnesaemia (Figure $1 \&$ Table 2 ).

Trace elements including magnesium were identified in different disease mechanisms. Cristiane H.S. et al. discussed role of magnesium in relation to diabetes that decreased intake of magnesium in diet, which may lead to diabetes mellitus and it was focused internationally. $\mathrm{HbA1C}$ was $8.0 \%$ with poor glycemic control [33]. In our hospital setups, there is less data of dietary magnesium is available in $\mathrm{Pa}$ kistani community so face great challenge of future for magnesium and diabetes mellitus managment. The glycemic control and the complications are also great challenges of hypomagnesaemia due to diabetes. In a study by Rodriguez-Moran 


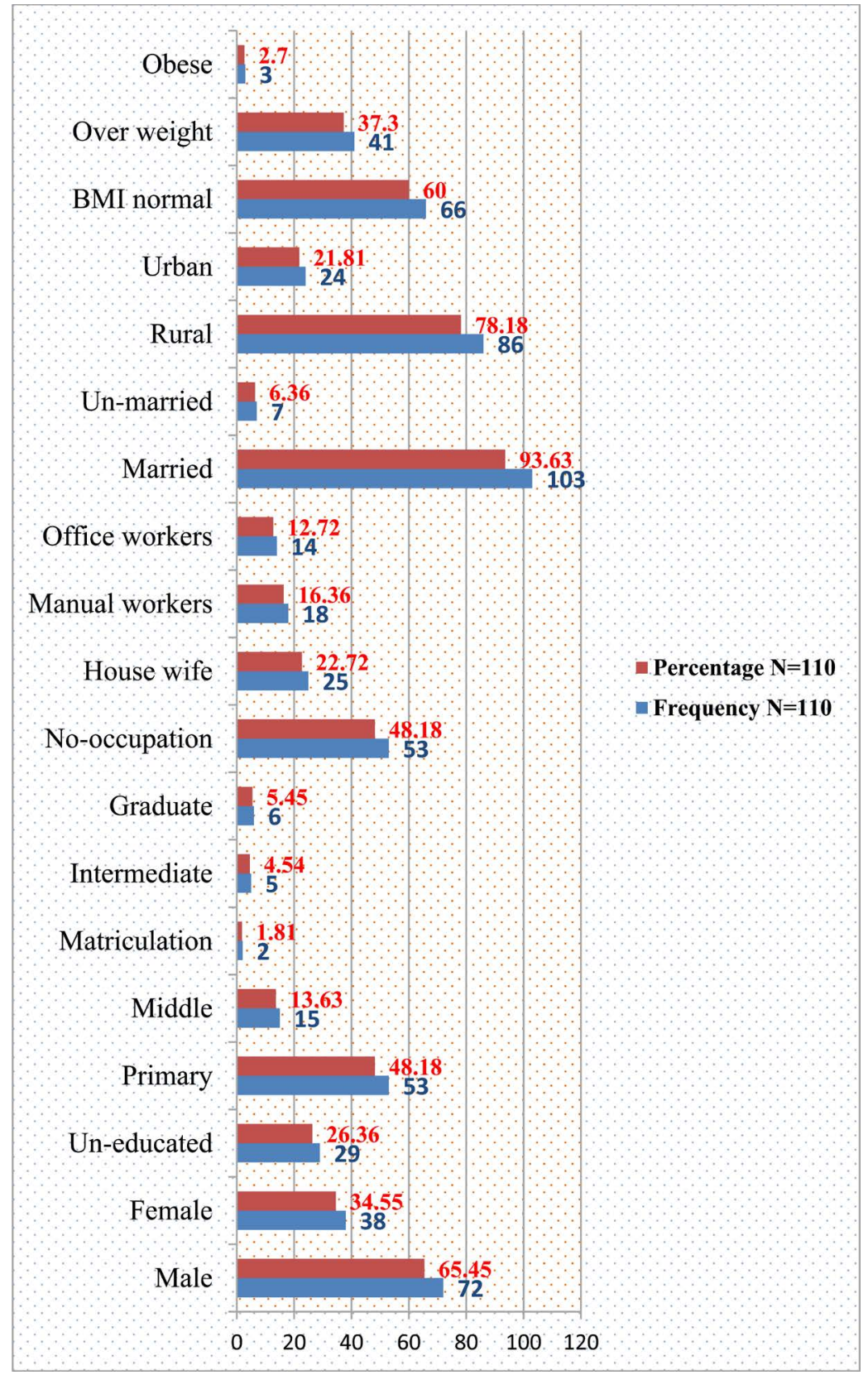

Figure 1. Demographical frequency distribution of the subjects.

et al. determined high incidence of hypomagnesaemia in $93.9 \%$ patients with diabetic foot ulcers as compared to $73.1 \%$ non-diabetic $(P=0.02)$ [34]. Findings of study are matchable with the present study that $60.9 \%$ population was reported with hypomagnesaemia (Table 2).

Diabetes disturbs serum magnesium level leading to development of complications concluded from Atherosclerosis Risk in Communities. Negative impact of hypomagnesaemia on vascular complications of diabetes is not yet clear. Hypomagnesaemia is not only common in foot ulcers but it can occur simultaneously also in other diabetic complications. Poly-neuropathy and dysfunction of platelets were identified risk factor in diabetic foot ulcers. T2DM is connected 
to complications other than foot ulcers. Studies had shown relationship of diabetic nephropathy and in non-diabetic nephropathy hypomagnesaemia is associated with worsening in kidney function in T2DM. Facts suggest connection among hypomagnesaemia and diabetic foot ulcers along with dyslipidemia and neurological irregularities as diabetic complications [35] [36] [37].

Serum magnesium is not true representative of intracellular contents because of very small quantities [38].

Our findings revealed the relation of magnesium level withT2 DM. Correlation was significant in our data related to $\mathrm{HbA1C}$ with Pearson Correlation at $-0.319^{* *}$ and (Sig.2-tailed) 0.001. Continuity Correction value was at 3.556 and (Sig.2-tailed) 1.059. While, the Fisher's Exact Test Exact Sig. (2-sided) was 0.036 and Exact Sig. (1-sided) was 0.036 (Table 3).

In our findings, high ratio of male population was magnesium deficient, because male mostly do the strenuous work which is more prone for injuries and complications. In era of technological advances and increasing approach it is necessary to explore aspects of disease and the factors affecting it. This study identified risk of foot ulcer due to hypomagnesaemia in T2DM. Since there is lack of information on this basic approach to the trace elements analysis, it is imperative that possible approach should be available for management of disease. Since PMCH is teaching hospital, it would give a positive support for proper management to avoid high morbidity and mortality.

\section{Conclusion}

Hypomagnesaemia observed as main finding in present study in patients suffering from Type $2 \mathrm{DM}$ with foot ulcers (grade I and II) which was found in 67 (60.9\%) out of total studied subjects. It was concluded that as duration of Diabetes along with duration of diabetic foot ulcer (Grade I and II) increases, the level of serum magnesium decreases. As the duration of Diabetes Mellitus increases, the severity of complications might also increase.

\section{Recommendations}

Serum magnesium analysis should be managed routinely in DM complications to control the severity of complications due to hypomagnesaemia. It is recommended that intermittent checking for proper assessment and treatment related to magnesium deficiency should be started immediately at earlier stages. Furthermore, it is suggested for large scale evaluation to find detailed data about the concerns of this study.

\section{Conflicts of Interest}

The authors declare that there are no conflicts of interest.

\section{Limitations}

Few studies available at national level evolved uncertainty regarding magnesium 
status in region on contrary disease prevalence are more common. Abundance of studies has been done internationally. Cost effectiveness is main problem in most of the government hospital laboratories because of limited facilities are available.

\section{References}

[1] Sean, F.D. (2006) What Is Diabetes: Diabetes Basic Facts Medicine International Number. Medicine, 34, 245-246.

[2] Masharani, U. (2008) Diabetes Mellitus \& Hypoglycemia. In: Tierney Jr., L.M., McPhee, S.J. and Papadakis, M.A., Eds., Current Medical Diagnosis \& Treatment, McGraw-Hill Education, Columbus, 1142-1190.

[3] Singh, N., et al. (2005) Preventing Foot Ulcers in Patients with Diabetes. JAMA, 293, 217-228. https://doi.org/10.1001/jama.293.2.217

[4] Reiber, G.E., et al. (1999) Causal Pathways for Incident Lower-Extremity Ulcers in Patients with Diabetes from Two Settings. Diabetes Care, 22, 157-162. https://doi.org/10.2337/diacare.22.1.157

[5] Sarah, W., et al. (2004) Global Prevalence of Diabetes. Diabetes Care, 27, 1047-1053. https://doi.org/10.2337/diacare.27.5.1047

[6] Shafique, M., et al. (2002) Beneficial Effects of Magnesium Supplementation in Diabetes Mellitus: An Animal Study. Pakistan Journal of Medical Research, 41, 73-76.

[7] Pham, P.C., et al. (2007) Hypomagnesaemia in Patients with Type 2 Diabetes. Clinical Journal of the American Society of Nephrology, 2, 366-373. https://doi.org/10.2215/CJN.02960906

[8] Zafar, A. (2001) Management of Diabetic Foot-Two Years' Experience. Journal of Ayub Medical College, 13, 14-16.

[9] Griffiths, G.D. (2002) Diabetic Foot Disease. In: Cuschieri, S.A., Ed., Essential Surgical Practice, CRC Press, Boca Raton, 785-794.

[10] Roariguez, M.M., et al. (2003) Oral Magnesium Supplementation Improves Insulin Sensitivity and Metabolic Control in Type 2 Diabetic Subjects. Diabetes Care, 26, 1147-1152. https://doi.org/10.2337/diacare.26.4.1147

[11] Lee, M. (2013) Basic Skills in Interpreting Laboratory Data. 5th Edition, American Society of Health-System Pharmacists, Bethesda.

[12] Lexi-Comp, Inc. (2015) Drug Information Handbook. A Comprehensive Resource for All Clinicians and Healthcare Professionals. 24th Edition, Lexi-Comp, Inc., Hudson.

[13] Bringhurst, F.R., et al. (2012) Bone and Mineral Metabolism in Health and Disease. In: Longo, D.L., Ed., Harrison's Principles of Internal Medicine, McGraw-Hill Global Education, Columbus.

[14] Williamson, M.A., et al. (2011) Wallach's Interpretation of Diagnostic Tests. 9th Edition, Wolters Kluwer/Lippincott Williams \& Wilkins Health, Philadelphia.

[15] Frier, B.M., et al. (2006) Diabetes Mellitus. In: Hunter, J.A., Ed., Principles and Practice of Medicine, Churchill Livingstone, Edinburgh, 805-847.

[16] James, B.W. (2008) Classification of Foot Lesion in Diabetic Patients. In: John, B.H. and Micheal, P.A., Eds., Levin and $O^{\prime}$ Neal s the Diabetic Foot, 7th Edition, Mosby Elsevier, Amsterdam, 221-226.

[17] DeValk, H.W. (1999) Magnesium in Diabetes Mellitus. The Netherlands Journal of Medicine, 54, 139-146. https://doi.org/10.1016/S0300-2977(99)00005-4 
[18] Rude, R.K. (1998) Magnesium Deficiency: A Cause of Heterogeneous Disease in Humans. Journal of Bone and Mineral Research, 13, 749-758. https://doi.org/10.1359/jbmr.1998.13.4.749

[19] Rude, R.K. (1992) Magnesium Deficiency and Diabetes Mellitus: Causes and Effects. Postgraduate Medicine, 92, 217-224. https://doi.org/10.1080/00325481.1992.11701494

[20] Nadler, J.L., et al. (1995) Disorders of Magnesium Metabolism. Endocrinology Metabolism Clinics of North America, 24, 623-641.

[21] Fujii, S., et al. (1982) Magnesium Levels in Plasma Erythrocyte and Urine in Patients with Diabetes Mellitus. Hormone and Metabolic Research, 14, 161-162. https://doi.org/10.1055/s-2007-1018954

[22] WHO Study Group (1985) Diabetes Mellitus. Technical Report Series 727, World Health Organization, Geneva.

[23] Mather, H.M., et al. (1979) Hypomagnesaemia in Diabetes. ClinChimActa, 95, 235-242. https://doi.org/10.1016/0009-8981(79)90364-4

[24] McNair, P., et al. (1978) Hypomagnesemia: A Risk Factor in Diabetic Retinopathy. Diabetes, 27, 1075-1077. https://doi.org/10.2337/diab.27.11.1075

[25] McNair, P., et al. (1982) Renal Hypomagnesemia in Human Diabetes Mellitus: Its Relation to Glucose Homeostasis. European Journal of Clinical Investigation, 12, 81-85. https://doi.org/10.1111/j.1365-2362.1982.tb00942.x

[26] Djurhuus, M.S., et al. (2000) Hyperglycemia Enhances Renal Magnesium Excretion in Type 1 Diabetic Patients. Scandinavian Journal of Clinical and Laboratory Investigation, 60, 403-409. https://doi.org/10.1080/003655100750019314

[27] Barbagallo, M., et al. (1993) Cellular Ionic Effects of Insulin in Normal Human Erythrocytes: A Nuclear Magnetic Resonance Study. Diabetologia, 36, 146-149. https://doi.org/10.1007/BF00400696

[28] Hwang, D.L., et al. (1993) Insulin Increases Intracellular Magnesium Transport in Human Platelets. The Journal of Clinical Endocrinology \& Metabolism, 76, 549-553.

[29] Berhane, S., et al. (2008) Hypomagnesemia in Ethiopians with Diabetes Mellitus. Ethnicity \& Disease, 18, 147-151.

[30] Ma, J., et al. (1995) Associations of Serum and Dietary Magnesium with cardiovascular Disease, Hypertension, Diabetes, Insulin, and Carotid Arterial Wall Thickness: The Atherosclerosis Risk in Communities Study. Journal of Clinical Epidemiology, 48, 927-940. https://doi.org/10.1016/0895-4356(94)00200-A

[31] White, J.R., et al. (1998) Magnesium and Diabetes: A Review. The Annals of Pharmacotherapy, 27, 775-780. https://doi.org/10.1177/106002809302700619

[32] Resnick, L.M., et al. (1988) Intracellular Free Magnesium in Hypertension: Relation to Peripheral Insulin Resistance. Journal of Hypertension, 6, 199-201. https://doi.org/10.1097/00004872-198812040-00059

[33] Cristiane, H.S., et al. (2006) Magnesium and Diabetes Mellitus. Their Relation Clinical Nutrition, 25, 554-562. https://doi.org/10.1016/j.clnu.2006.03.003

[34] RodríguezMorán, M., et al. (2001) Low Serum Magnesium Levels and Foot Ulcers in Subjects with Type 2 Diabetes. Archives of Medical Research, 32, 300-303. https://doi.org/10.1016/S0188-4409(01)00298-3

[35] Liao, F., et al. (1998) Is Low Magnesium Concentration a Risk Factor for Coronary Heart Disease: The Atherosclerosis Risk in Communities (ARIC) Study. American Heart Journal, 136, 480-490. https://doi.org/10.1016/S0002-8703(98)70224-8 
[36] Pham, P.C., et al. (2005) Lower Serum Magnesium Levels Are Associated with More Rapid Decline of Renal Function in Patients with Diabetes Mellitus Type 2. Clinical Nephrology, 63, 429-436. https://doi.org/10.5414/CNP63429

[37] Sales, C.R. (2006) Magnesium and Diabetes Mellitus: Their Relation. Clinical Nutrition, 225, 554-562. https://doi.org/10.1016/j.clnu.2006.03.003

[38] Ford, E.S., et al. (2003) Dietary Magnesium Intake in a National Sample of US Adults. The Journal of Nutrition, 133, 2879-2882.

https://doi.org/10.1093/jn/133.9.2879 